\title{
The Influence of Engine Speed on HCCI Combustion Characteristics Fueled with N-heptane
}

\author{
XUE Le ${ }^{a}$ and ZHANG Chunhua ${ }^{b}$ \\ School of Automobile, Chang'an University, Xi'an, People's Republic of China \\ axuele1988@126.com, bchzzz@126.com
}

Keywords: Homogeneous Charge Compression Ignition, engine speed, combustion, n-heptane

\begin{abstract}
In order to research the influence of engine speed on HCCI combustion, the experiment was conducted in a retrofitted engine to realize HCCI combustion mode. The results indicated that engine speed has a weak influence on combustion phase. But with the increase of engine speed, two-stage heat release is so noticeable and the low-temperature oxidation process goes well.
\end{abstract}

\section{Introduction}

Facing with the stringent emission laws and shortage of oil fuel, high-efficiency and low-emission combustion is urgently needed for internal combustion engine. Compared with gasoline engine, there are two main overwhelming superiorities of diesel engine. Diesel engine is becoming more and more popular due to its higher thermal efficiency and low emissions characteristics. But the advantages of conventional diesel engines fade because of the famous trade-off limitation between nitrogen oxides (NOx) and particulate matter (PM). Fortunately, In recent decades, a new combustion mode, homogeneous charge compression ignition (HCCI), has been realized to achieve low emissions of NOx and PM simultaneously as well as keep high thermal efficiency.

To reduce the emissions and combustion temperature, pre-mixed homogeneous mixture is introduced to HCCI engine instead of in-cylinder fuel injection. That is to say, there is no diffusion combustion in HCCI engine theoretically. However, combustion chain is broken down due to the low combustion temperature [1], as a result, the level of hydrocarbon (HC) emission is slightly higher than that of conventional diesel engines. HCCI combustion is dominated by the chemical kinetics and there is no way to control the combustion directly. Small changes of operation condition may bring great variations in the properties of the mixture, as a result, the combustion is unstable and emission deterioration is so serious.

In previous research works, some experiments have been done to research the combustion fueled with n-heptane in an HCCI engine. M.R. Kumar et al. [2] studied the influences of air-fuel ratios and intake temperatures on cycle-to-cycle variations, but no attention has been paid to different engine speeds. Numerical study on the heat transfer of n-heptane combustion using negative valve overlap (NVO) was investigated by Z. Bouali et al. [3]. The experimental research conducted by Morteza F. et al. [4] showed that exhaust gas recirculation (EGR) has profound effect on combustion phase and combustion duration. The simulation study of HCCI combustion fueled with butanol/heptane was studied by Visakhamoorthy S. et al [5]. Z.L. Zheng and M.F. Yao [6] tried to use charge stratification to control the HCCI combustion. Some additives were added in the n-heptane HCCI combustion experiment to control the combustion timing [7]. Some papers are available about the influence of intake temperature, excessive air coefficient and under other conditions on combustion characteristics $[8,9,10,11,12]$.

As we all know, the greatest obstacles in HCCI engine are the control of combustion and the narrow operation range. And it is worth noting that the engine speed also plays an important role in the combustion characteristics.

\section{Methods}

Test Equipments. CT2100Q, a-double-cylinder, four strokes, natural aspiration direct-injection diesel engine is used in the experiment. The specific parameters of the engine are shown in Table 1. 
Table1 The specific parameters of the engine

\begin{tabular}{l|l}
\hline Items/[units] & parameters \\
\hline Shape of combustion chamber & $\omega$ \\
Cylinder bore $\times$ piston stroke/[mm] & $100 \times 105$ \\
Displacement/[L] & 1.65 \\
Compression ratio & $17: 1$ \\
Intake valve opening angle & $17\left[{ }^{\circ} \mathrm{CA}\right] \quad$ BTDC \\
Intake valve closing angle & $43\left[{ }^{\circ} \mathrm{CA}\right] \quad$ ABDC \\
Exhaust valve opening angle & $47\left[{ }^{\circ} \mathrm{CA}\right] \quad$ BBDC \\
Exhaust valve closing angle & $17\left[{ }^{\circ} \mathrm{CA}\right] \quad$ ATDC \\
\hline
\end{tabular}

In order to realize homogeneous charge compression ignition, the $2 \#$ cylinder is altered to achieve independent intake and exhaust systems. For the $2 \#$ cylinder, an electric heater is fixed on the intake pipe to control intake temperature. The fuel supply system of $2 \#$ cylinder is independent and the fuel injector is fixed in the intake pipe where keeps 60 centimeter from the intake valve of the $2 \#$ cylinder. The signal of fuel injection is obtained from the Hall sensor which is fixed on the camshaft. An independent control circuit is used for adjusting the pulse width of fuel injection. CB566 combustion analyzer is used to collect the in-cylinder pressure values.

Test Method. The 1\# cylinder is run in its conventional mode (supply diesel fuel to the 1\# cylinder), and the $2 \#$ cylinder is the HCCI cylinder. When temperature of cooling water and lubricating oil reach the normal level, the diesel fuel supplied to $1 \#$ cylinder is cut off, and at the same time, n-heptane fuel is supplied to the $2 \#$ cylinder. In the test, the signal of the pressure of the cylinder is collected every 0.25 crank angle by the combustion analyzer. 60 consecutive cycles were tested under every operating condition. So the average indicator diagram is gained, and the pressure rise rate and heat release rate can be calculated.

\section{Results and Discussion}

In-cylinder Pressure and Pressure Rise Rate. To investigate the influence of engine speed on combustion in an HCCI engine, the experiment is conducted under the intake temperature of $50^{\circ} \mathrm{C}$ $\left(\mathrm{Tin}=50^{\circ} \mathrm{C}\right)$ and excessive air coefficient of $2.1(\lambda=2.1)$.

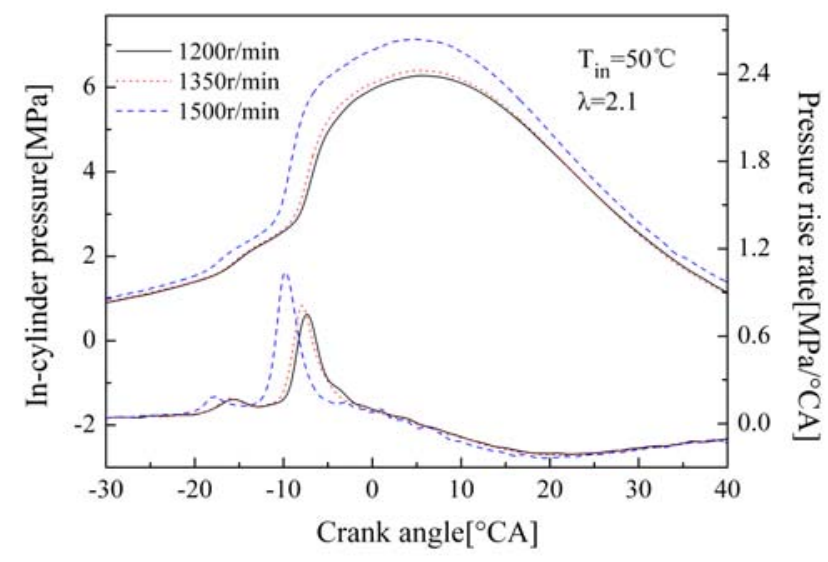

Fig. 1 In-cylinder pressure and PRR with engine speed

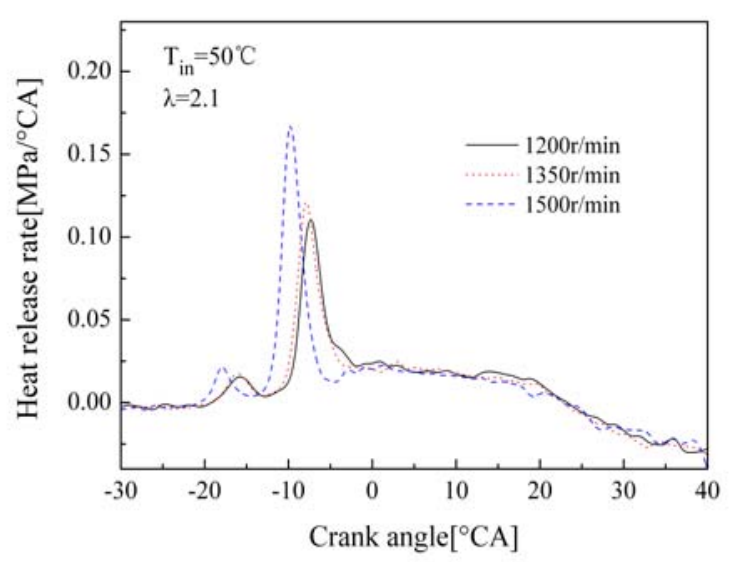

Fig. 2 HRR with engine speed

Fig. 1 and Fig. 2 show the in-cylinder pressure, pressure rise rate (PRR) and heat release rate (HRR) curves. With the increase of engine speed, the peak in-cylinder pressure, pressure rise rate and heat release rate increase gradually, and the occurrence of these values becomes early. It is worth noting that the engine speed has a weak influence on in-cylinder pressure and PRR, and HRR has a noticeable change of its value with the variation of engine speed. What's more, it can be included from Fig. 2 that engine speed affects the combustion phase slightly. Another trend obtained from 
Fig. 2 is that a typical two-stage heat release phenomenon, especially under $1500 \mathrm{r} / \mathrm{min}$. The reason is that high engine speed contributes to the formation of intake swirl, and the low-temperature oxidation process takes place at an early crank angle.

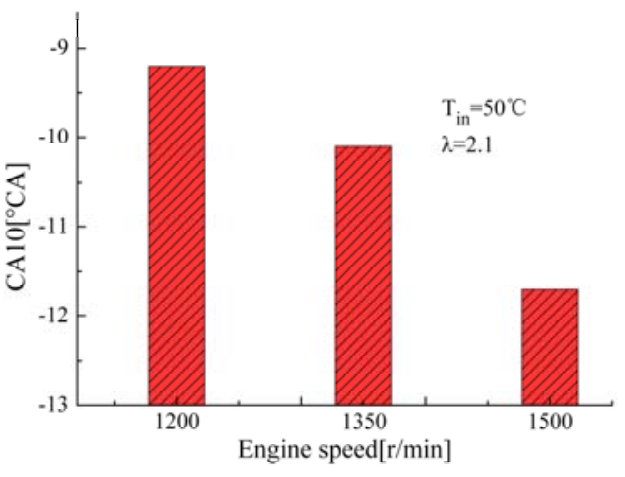

Fig. 3 CA10 with engine speed

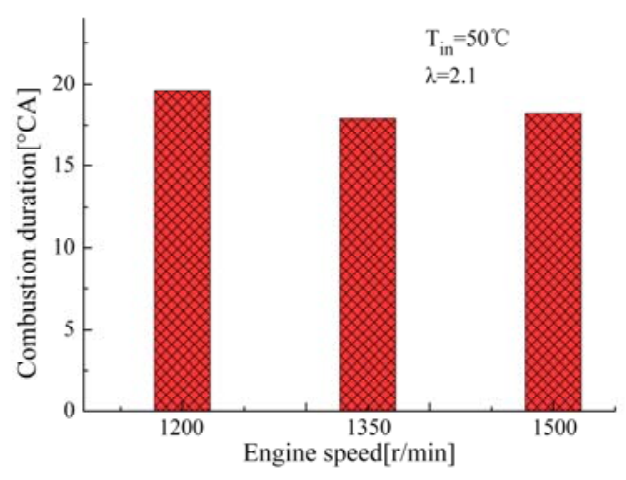

Fig. 4 Combustion duration with engine speed

CA10 and Combustion Duration. To illustrate the influence of engine speed on combustion, Fig. 3 and Fig. 4 give the bar graphs of CA10 and combustion duration. CA10 is defined as the corresponding crank angle when $10 \%$ fuel is burnt and it is usually regarded as the starting of combustion. Compare with 1200r/min and $1350 \mathrm{r} / \mathrm{min}$, an early combustion occurs under the engine speed of $1500 \mathrm{r} / \mathrm{min}$. But another interesting trend from Fig. 4 is that combustion duration changes slightly with the engine speed. With the increase of engine speed, heat loss from in-cylinder mixture to cylinder wall decreases. More and more radicals occurred in the oxidation process, especially $\bullet \mathrm{OH}$, and it is believed the most useful radical in the event of auto-ignition. However, volumetric efficiency decreases with the increase of engine speed and the heat release in a whole cycle is disturbed. As a result, the combustion duration changes slightly because of these comprehensive factors.

\section{Conclusions}

In general, engine speed has a relatively weak influence on HCCI combustion. It affects HRR values profoundly but combustion phase slightly. That is to say, the combustion is not sensitive to engine speed variations to a certain extent. What's more, the two-stage heat release process is so remarkable under high engine speed. A good low-temperature oxidation means a good combustion process in the cylinder and the research is so valuable that operation boundaries of HCCI engine can be tested according to these analyses. Furthermore, it will contribute to the extension of operation range to a higher engine speed in an HCCI engine.

\section{Acknowledgements}

This work was supported by the project of Natural Science Foundation of Shaanxi province (Program NO. 2012JQ7031). The authors are grateful to the science technology department of Shaanxi province for their financial support.

\section{Reference}

[1] J. Dec: SAE paper, NO. 2002-01-1309 (2002).

[2] R. Kumar Maurya and A. Avinash Kumar: Appl. Energ. Vol. 88 (2011), p. 1153-1163

[3] Z. Bouali, C. Pera and J. Reveillon: Combust. Flame. Vol.159 (2012), p. 2056-2068

[4] R.M. Fathi, M.K. Saray and D. Checkel: Appl. Energ. Vol. 88 (2011), p. 4719-4724

[5] S. Visakhamoorthy, J.Z. Wen, S. Sivoththaman and C.R. Koch: Appl. Energ. Vol. 94 (2012), p. $166-173$

[6] Z. Zheng and M. Yao: Fuel Vol. 88 (2009), p. 354-365 
[7] X.C. Lü, L.B. Ji, L.L. Zu, Y.C. Hou, C. Huang and Z. Huang: Combust. Flame Vol. 149 (2007), p. $261-270$

[8] C.H. Zhang, J.R. Pan, J.J. Tong and J. Li: Procedia Environmental Sciences Vol. 11 (2011), p. $1119-1127$

[9] H. Machrafi and S.Cavadiasa: Fuel Processing Technol. Vol. 89 (2008), p. 1218-1226

[10]Z.L. Zheng and M.F. Yao: Transactions of CSICE Vol. 24 (2006), p. 421-427

[11]N. Ali Yousefzadi, R.K. Saray and A.Rahimi: Fuel Vol. 90 (2011), p. 1508-1514

[12]H. Machrafi, S. Cavadias and J. Amouroux: Appl. Energ. Vol. 85 (2008), p. 755-764 